\title{
Preparation, Structure and Investigations of BEDT-TTF Trihalides
}

\author{
H. Endres, M. Hiller, and H. J. Keller*
}

Anorganisch-Chemisches Institut der Universität Heidelberg, Im Neuenheimer Feld 270, D-6900 Heidelberg 1, FRG

K. Bender, E. Gogu, I. Heinen, and D. Schweitzer

Abt. für Molekulare Physik, Max-Planck-Institut für Medizinische Forschung, Jahnstraße 29, D-6900 Heidelberg 1, FRG

Z. Naturforsch. 40 b, 1664-1671 (1985); received July 8, 1985

Structure, Organic Metals, Superconductors

Crystals of the $\beta$-phases of (BEDT-TTF $)_{2} \mathrm{Br}-\mathrm{I}-\mathrm{Br}(1)$ and $(\mathrm{BEDT}-\mathrm{TTF})_{2} \mathrm{I}-\mathrm{I}-\mathrm{Br}$ (2) have been isolated by electrocrystallization. The solids can be obtained using different tetrabutylammonium trihalides containing iodine and bromine as supporting electrolytes. Cyclovoltammetric results show clearly that the trihalide anions are involved in the oxidation reactions near the anode which finally lead to the crystals.

$1 \mathrm{C}_{20} \mathrm{H}_{16} \mathrm{Br}_{2} \mathrm{IS}_{16}, \mathrm{M}_{\tau}=1056.01$, and $2 \mathrm{C}_{20} \mathrm{H}_{16} \mathrm{BrI}_{2} \mathrm{~S}_{16}, \mathrm{M}_{r}=1103.01$ are isomorphous, crystallizing in the triclinic space group $\mathrm{P} \overline{1}$, with $Z=1$. Unit cell parameters for $\mathbf{1}: a=6.5979(6) \AA, b=$ 8.998(1) $\AA, c=15.138(3) \AA, a=94.03(1)^{\circ}, \beta=95.13(1), \gamma=110.28(1), V=834.7 \AA^{3}$, and for 2: $a=6.606(2) \AA, b=9.047(6) \AA, c=15.229(6) \AA, a=94.28(2)^{\circ}, \beta=95.34(2), \gamma=109.92(2)$, $\mathrm{V}=846.5 \AA^{3}$.

The different sizes of the $\mathrm{Br}_{2} \mathrm{I}^{-}$and $\mathrm{BrI}_{2}{ }^{-}$counterions lead to different intra- and interstack $\mathrm{S} \cdots \mathrm{S}$ contacts in the solids thus influencing the physical properties. An additional $\mathrm{BrI}_{2}{ }^{-}$phase with a modulation of the above-described structure could be found. Some relevant physical properties of $\mathbf{1}$ and $\mathbf{2}$ are reported.

\section{Introduction}

Since the discovery of superconductivity in the organic metal $\beta$-(BEDT-TTF $)_{2} \mathbf{I}_{3}$ at ambient pressure [1-3], efforts in different laboratories [4-6] aim at the preparation of other promising trihalide salts of BEDT-TTF** $^{*}$. The final hope is the advancement of a relation between the size and the redox properties of the trihalide counterions on one side and the lattice structure of the BEDT-TTF salts leading to distinct physical properties of the solids on the other hand. This relation can possibly be found by a systematic variation of the trihalide ions in the BEDT-TTF solids, by elucidating their structures, and finally by comparing their physical properties.

There is one major electro-chemical obstacle on the route to this goal. In contrast to all other so far reported conducting salts of organic donors with counterions like $\mathrm{ClO}_{4}{ }^{-}, \mathrm{BF}_{4}{ }^{-}, \mathrm{AsF}_{6}{ }^{-}, \mathrm{PF}_{6}{ }^{-}$etc. in the trihalides containing iodide the primary anode reaction is not the oxidation of the donor but the oxidation of the trihalide anion. This leads to further reactions involving elemental halogens. Especially noteworthy are symmetrization and/or other rear-

* Reprint requests to Prof. Dr. H. J. Keller.

** BEDT-TTF = bis(ethylenedithio)tetrathiofulvalene, $\mathrm{C}_{10} \mathrm{~S}_{8} \mathrm{H}_{8}$.

Verlag der Zeitschrift für Naturforschung, D-7400 Tübingen 0340-5087/85/1200-1664/\$ 01.00/0 rangement reactions, which finally yield solids with unexpected counterion compositions. In the following we would like to point to this problem by reporting the synthesis, structure, and physical properties of two interesting trihalide salts of BEDT-TTF.

\section{Experimental}

\section{Preparation}

BEDT-TTF [7] and tetra( $n$-butylammonium)triiodide [8] were obtained as described earlier, while the other tetra( $n$-butylammonium)trihalides $\left(\mathrm{I}-\mathrm{I}-\mathrm{Br}^{-}, \mathrm{I}-\mathrm{Br}-\mathrm{I}^{-}, \mathrm{Br}-\mathrm{Br}-\mathrm{I}^{-}\right.$and $\mathrm{Br}-\mathrm{I}-\mathrm{Br}^{-}$) were prepared in way analogous to procedures reported for the ammonium salts [9]. All compounds were purified by recrystallization and identified by their elemental analyses.

\section{Cyclovoltammetry}

A routine three electrode arrangement, with a saturated calomel half-cell as reference electrode and platinum sheets as counter and working electrodes, was used for the cyclovoltammogramms. The measurements were carried out under argon atmosphere and with tetrabutylammonium perchlorate in absolute methylene chloride as electrolyte.

\section{Electrocrystallization}

The crystals for the following investigations were obtained by electrocrystallization in an arrangement 
described earlier $[10,11]$. Tetrahydrofuran (Merck, Uvasol) was used as solvent. The symmetrical tetrabutylammonium diiodobromide as well as the symmetrical and asymmetrical tetrabutylammonium dibromoiodide were used as supporting electrolytes. The crystals were grown galvanostatically $(\approx 15 \mu \mathrm{A})$ with $1.25 \mathrm{~V}$ potential at the outer electrodes. Solely BEDT-TTF trihalides containing iodide can be grown with such a small potential. The typical other electrolyte anions (e.g. $\left.\mathrm{ClO}_{4}^{-}\right)$require higher potentials for electro-deposition (at least $1.75 \mathrm{~V}$ ). In all cases $\alpha$ - and $\beta$-phases of the BEDT-TTF trihalides are obtained by this procedure.

\section{$X$-ray investigations}

For the X-ray investigations prismatic trunks of crystals of the $\beta$-phases $\left(0.10 \times 0.20 \times 0.25 \mathrm{~mm}^{3}\right)$ were mounted on top of glass capillaries. Lattice parameters were derived from the setting angles of $25 \mathrm{re}$ flections (Syntex R3 diffractometer, monochromated MoK $_{\alpha}$ radiation). An empirical absorption correction using $\psi$-scans was applied for both crystals. Details are listed in Table I.

The coordinates of the triiodide salt [12] were taken as starting values. Refinement by cascade matrix least squares based on $F$, with weights $w=1 / \sigma^{2}(F)$ was finally carried out with anisotropic temperature factors. In the $\mathrm{I}_{2} \mathrm{Br}^{-}$salt the asymmetric anion
$(\mathrm{I}-\mathrm{I}-\mathrm{Br})^{-}$has its central atom on a crystallographic inversion center, and the lateral positions are statistically occupied by I and $\mathrm{Br}$. In the refinement this was accounted for by inserting an "IBr" species, the scattering factor of which was the average of $\mathrm{I}$ and $\mathrm{Br}$. The temperature factor for this species made it likely, however, that the scattering power should be somewhat larger, probably due to contamination with $\mathrm{I}_{3}{ }^{-}$. Trials yielded an optimum $R$ and a reasonable temperature parameter, if the site occupation factor was set at 1.09. H positions did not show up clearly in difference Fourier maps. Those of the $\mathrm{I}_{2} \mathrm{Br}^{-}$salt were inserted at calculated positions and refined in a riding model, lowering $R_{\mathrm{w}}$ from 0.044 to 0.042 . In the $\mathrm{IBr}_{2}{ }^{-}$salt the $R$ value did not change when calculated $\mathrm{H}$ positions were included. Hence they were omitted in the refinement.

Calculations were performed with the SHELXTL program package [13] on a Nova 3 computer using scattering factors, including anomalous dispersion, from International Tables for X-ray Crystallography [14]. Plots were drawn on a Tektronix plotter with SHELXTL.

\section{Results and Discussion}

\section{Electrochemical investigations}

BEDT-TTF shows a reversible redox step at $+0.63 \mathrm{~V}$ (peak potential) and an additional irrevers-

\begin{tabular}{lcc}
\hline Space group & $\begin{array}{l}(\mathrm{BEDT}-\mathrm{TTF})_{2} \mathrm{BrIBr} \\
\mathrm{P} \overline{1}\end{array}$ & $\begin{array}{l}(\mathrm{BEDT}-\mathrm{TTF})_{2} \mathrm{I}-\mathrm{I}-\mathrm{Br} \\
\mathrm{P} \overline{1}\end{array}$ \\
\hline$a(\AA)$ & $6.5979(6)$ & $6.606(2)$ \\
$b$ & $8.998(1)$ & $9.047(6)$ \\
$c$ & $15.138(3)$ & $15.229(6)$ \\
$\alpha\left(^{\circ}\right)$ & $94.03(1)$ & $94.28(2)$ \\
$\beta$ & $95.13(1)$ & $95.34(2)$ \\
$\gamma$ & $110.28(1)$ & $109.92(2)$ \\
$\mathrm{V}\left(\AA^{3}\right)$ & 834.7 & 846.5 \\
$Z$ & 1 & 1 \\
$\mathrm{~F}(000)$ & 515 & 533 \\
$\mu\left(\mathrm{cm}^{-1}\right)$ & 43 & 39.7 \\
$\mathrm{M}_{\mathrm{r}}$ & 1056.01 & 1103.01 \\
$\mathrm{~d}_{\text {cal }}\left(\mathrm{gcm}^{-3}\right)$ & 2.10 & 2.16 \\
scan mode & & $70^{\circ}$ \\
$2 \theta_{\text {max }}$ & $60^{\circ}$ & 7455 \\
refl. measured & 4870 & 3353 \\
refl. observed & 2794 & 0.021 \\
$(\mathrm{I}>2.5 \sigma(\mathrm{I}))$ & & 178 \\
$R_{\text {int }}$ & 0.026 & $0.045,0.042$ \\
parameters & 178 & 2.53 \\
$R, R_{\mathrm{w}}$ & $0.072,0.065$ & 0.05 \\
goodn. of fit & 4.09 & $1.1 \mathrm{e} \AA^{-3}$ \\
max. shift/esd & 0.1 & \\
max. diff. & &
\end{tabular}

Table 1. Crystal data, measurement parameters, and refinement results. 
ible oxidation at $+0.94 \mathrm{~V}$. The second oxidation step leads to charged particles as indicated by the appreciable polarization current at the working electrode. By using a rotating platinum disc as working electrode (as in a polarographic arrangement), it can be shown that two one-electron oxidation steps occur by oxidizing the donor BEDT-TTF.

Triiodide can be reduced below $+0.3 \mathrm{~V}$ to iodide ions. Further oxidation steps at $+0.4 \mathrm{~V}$ and $+0.7 \mathrm{~V}$ (peak potentials) lead back to $\mathrm{I}_{2}^{-}, \mathrm{I}_{5}{ }^{-}$or iodine radicals. The latter assumption could explain the following fact: mixtures of the donor ET with counter ions like $\mathrm{ClO}_{4}^{-}, \mathrm{BF}_{4}^{-}, \mathrm{PF}_{6}^{-}$, e.g., need a higher potential (by $0.45 \mathrm{~V}$ ) for electrocrystallization than in the case of (BEDT-TTF) $)_{2} \mathrm{I}_{3}$. In our preparative two electrode arrangement only (BEDT-TTF) ${ }_{2} \mathrm{I}_{3}$ and none of the other BEDT-TTF salts could be produced with the normally used $1.25 \mathrm{~V}$ potential.

One has to assume, therefore, that the production of iodine radicals is a primary step in the electrocrystallization of (BEDT-TTF $)_{2} \mathbf{I}_{3}$. In situ produced iodine radicals would be able to oxidize the donor or other trihalide ions in the solution. The produced BEDT-TTF cations will then crystallize with $\mathrm{I}_{3}{ }^{-}$. In any case it seems to be clear, that the oxidation of BEDT-TTF to solid radical salts in the presence of $\mathrm{I}_{3}{ }^{-}$or trihalide ions containing iodine follows a dif-

Table II. I-I- $\mathrm{Br}^{-}$salt: atom coordinates $\left(\times 10^{4}\right)$ and equivalent isotropic temperature factors $\left(\AA^{2} \times 10^{3}\right)$ defined as $1 / 3$ of the trace of the orthogonalized $U_{1}$ tensor. "Ibr" means the statistically occupied $\mathrm{I}$ and $\mathrm{Br}$ position.

\begin{tabular}{lrrrr}
\hline Atom & \multicolumn{1}{c}{$\boldsymbol{x}$} & \multicolumn{1}{l}{$\boldsymbol{y}$} & $\mathrm{U}$ \\
\hline I & 0 & 0 & 0 & $54(1)$ \\
Ibr & $-3916(1)$ & $-2534(1)$ & $145(1)$ & $44(1)$ \\
S(1) & $4630(2)$ & $7391(2)$ & $4480(1)$ & $41(1)$ \\
S(2) & $980(2)$ & $8534(2)$ & $4293(1)$ & $42(1)$ \\
S(3) & $2803(2)$ & $5697(2)$ & $6199(1)$ & $38(1)$ \\
S(4) & $-813(2)$ & $6874(2)$ & $5988(1)$ & $39(1)$ \\
S(5) & $6423(3)$ & $8624(2)$ & $2880(1)$ & $57(1)$ \\
S(6) & $2115(3)$ & $10039(2)$ & $2676(1)$ & $61(1)$ \\
S(7) & $1978(2)$ & $4614(2)$ & $7949(1)$ & $48(1)$ \\
S(8) & $-2359(2)$ & $6038(2)$ & $7691(1)$ & $48(1)$ \\
C(1) & $2268(7)$ & $7459(5)$ & $4877(3)$ & $32(2)$ \\
C(2) & $1510(7)$ & $6755(5)$ & $5595(3)$ & $32(2)$ \\
C(3) & $4407(8)$ & $8420(6)$ & $3571(3)$ & $35(2)$ \\
C(4) & $2735(8)$ & $8944(6)$ & $3485(3)$ & $36(2)$ \\
C(5) & $1181(7)$ & $5491(5)$ & $7059(3)$ & $30(2)$ \\
C(6) & $-467(7)$ & $6043(5)$ & $6962(3)$ & $32(2)$ \\
C(7) & $6261(9)$ & $10240(7)$ & $2340(4)$ & $60(3)$ \\
C(8) & $4166(10)$ & $10231(8)$ & $1977(4)$ & $70(3)$ \\
C(9) & $224(14)$ & $4857(14)$ & $8710(5)$ & $133(6)$ \\
C(10) & $-1640(14)$ & $4995(12)$ & $8518(6)$ & $120(6)$ \\
\hline
\end{tabular}

ferent mechanism compared to the electrocrystallization in the presence of anions like $\mathrm{ClO}_{4}{ }^{-}, \mathrm{BF}_{4}{ }^{-}$or $\mathrm{PF}_{6}{ }^{-}$.

The cyclovoltagramms hint to another speciality in reactions with trihalides as counter ions. The symmetric ions $\mathrm{I}-\mathrm{Br}-\mathrm{I}^{-}$and $\mathrm{Br}-\mathrm{I}-\mathrm{Br}^{-}$both show clear oxidation peaks at $+0.35 \mathrm{~V},+0.7 \mathrm{~V}$ and $+1.2 \mathrm{~V}$. The identical diagrams indicate that both compounds are oxidized electrochemically to the same species. This finding explains the surprising fact that electrocrystallization of BEDT-TTF in the presence of $\mathrm{I}-\mathrm{Br}-\mathrm{I}^{-}, \mathrm{Br}-\mathrm{Br}-\mathrm{I}^{-}$or $\mathrm{Br}-\mathrm{I}-\mathrm{Br}^{-}$yield the identical compound with only $\mathrm{Br}-\mathrm{I}-\mathrm{Br}^{-}$counterions in the crystal. It has, therefore, to be assumed that $\mathrm{I}-\mathrm{Br}-\mathrm{I}^{-}$is converted at least partially into $\mathrm{Br}-\mathrm{I}-\mathrm{Br}^{-}$during the electrolysis.

\section{Crystallographic investigations}

The two $\beta$-phase salts (BEDT-TTF) ${ }_{2} \mathrm{I}_{2} \mathrm{Br}$ and (BEDT-TTF $)_{2} \mathrm{IBr}_{2}$ are isomorphous with each other and with the $\beta$-phase of (BEDT-TTF) ${ }_{2} \mathbf{I}_{3}$. Atom coordinates are listed in Table $\mathrm{II}$ and $\mathrm{III}^{*}$. Bond distances

- Lists of anisotropic temperature factors and observed and calculated structure factors have been deposited with the Fachinformationszentrum Energie, Physik, Mathematik, D-7514 Eggenstein-Leopoldshafen 2, FRG. Copies may be obtained quoting the deposition number CSD 51599, the authors, and the journal reference.

Table III. $\mathrm{Br}-\mathrm{I}-\mathrm{Br}^{-}$salt: atom coordinates and equivalent isotropic temperature factors, analogous to Table II.

\begin{tabular}{lrrrr}
\hline Atom & \multicolumn{1}{c}{$x$} & \multicolumn{1}{l}{$y$} & $\mathrm{U}$ \\
\hline $\mathrm{I}$ & \multicolumn{1}{c}{0} & 0 & 0 & $59(1)$ \\
$\mathrm{Br}$ & $-3773(2)$ & $-2524(2)$ & $138(1)$ & $62(1)$ \\
$\mathrm{S}(1)$ & $4649(4)$ & $7397(4)$ & $4476(2)$ & $45(1)$ \\
$\mathrm{S}(2)$ & $1005(5)$ & $8539(4)$ & $4284(2)$ & $47(1)$ \\
$\mathrm{S}(3)$ & $2814(4)$ & $5706(4)$ & $6210(2)$ & $43(1)$ \\
S(4) & $-815(5)$ & $6887(4)$ & $5998(2)$ & $44(1)$ \\
S(5) & $6456(5)$ & $8615(4)$ & $2859(2)$ & $59(1)$ \\
S(6) & $2169(5)$ & $10036(4)$ & $2643(3)$ & $68(2)$ \\
S(7) & $1977(5)$ & $4621(4)$ & $7974(2)$ & $54(1)$ \\
S(8) & $-2388(5)$ & $6028(4)$ & $7711(2)$ & $53(1)$ \\
C(1) & $2341(16)$ & $7495(12)$ & $4886(7)$ & $40(4)$ \\
C(2) & $1564(16)$ & $6771(12)$ & $5601(7)$ & $37(4)$ \\
C(3) & $4440(16)$ & $8416(12)$ & $3563(7)$ & $39(4)$ \\
C(4) & $2779(16)$ & $8938(12)$ & $3464(7)$ & $40(4)$ \\
C(5) & $1173(16)$ & $5490(12)$ & $7068(7)$ & $36(4)$ \\
C(6) & $-463(16)$ & $6035(12)$ & $6978(7)$ & $36(4)$ \\
C(7) & $6282(20)$ & $10265(16)$ & $2283(10)$ & $71(7)$ \\
C(8) & $4252(22)$ & $10241(19)$ & $1948(10)$ & $84(8)$ \\
C(9) & $264(27)$ & $5013(24)$ & $8803(10)$ & $107(10)$ \\
C(10) & $-1890(24)$ & $4772(21)$ & $8503(10)$ & $94(9)$ \\
\hline
\end{tabular}




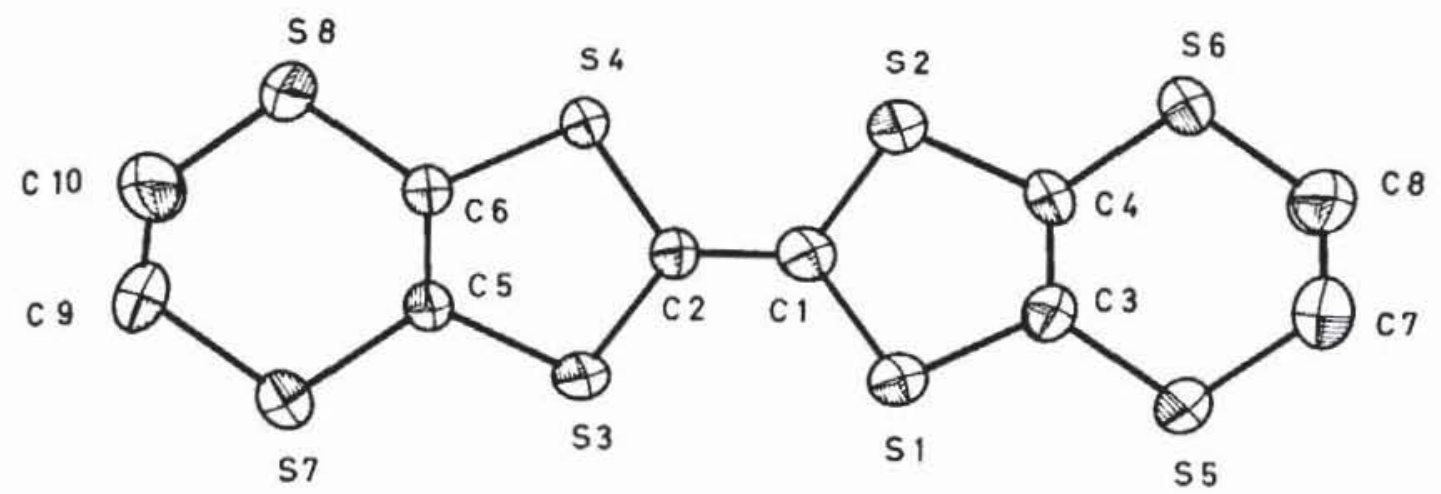

Fig. 1. The numbering scheme in the (BEDT-TTF) ${ }^{1 / 2+}$ cations. The thermal ellipsoids ( $50 \%$ probability) are those of the $\mathrm{IBr}_{2}{ }^{-}$salt.

(A)

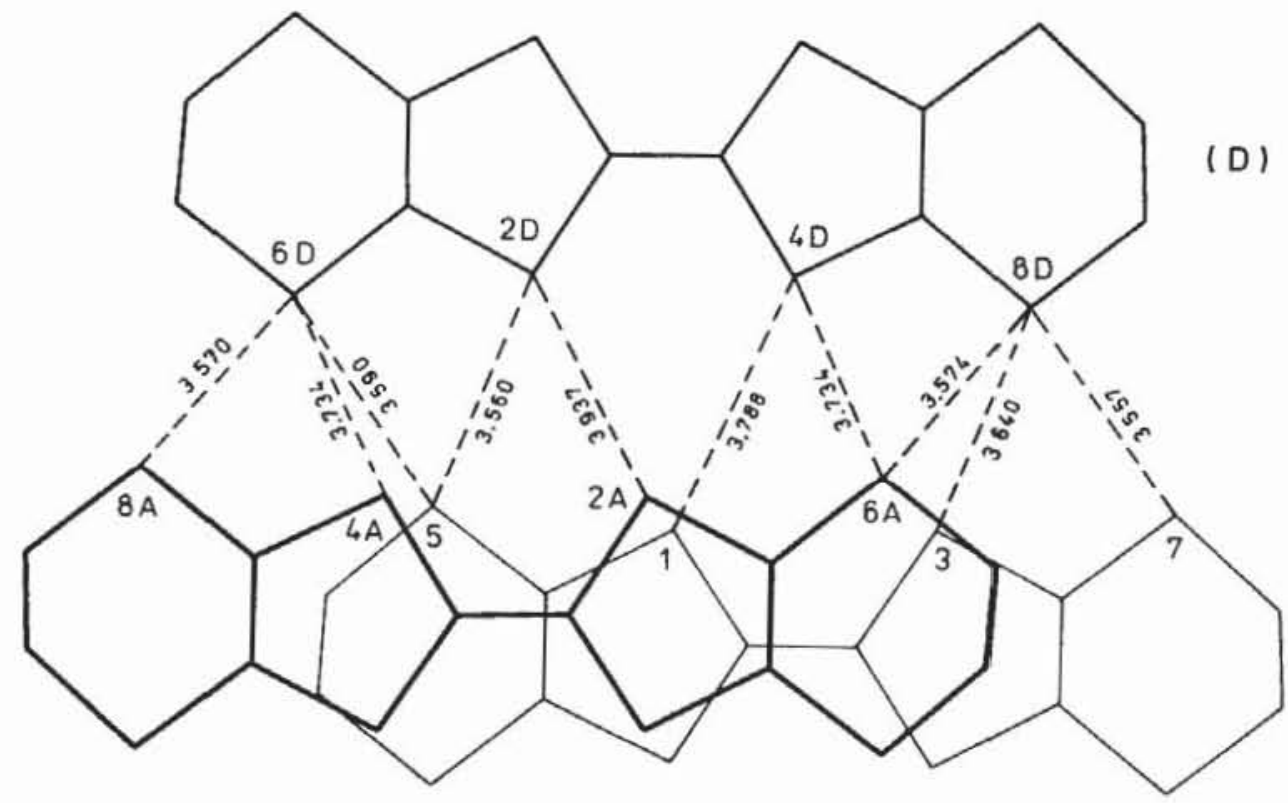

a)

(A)

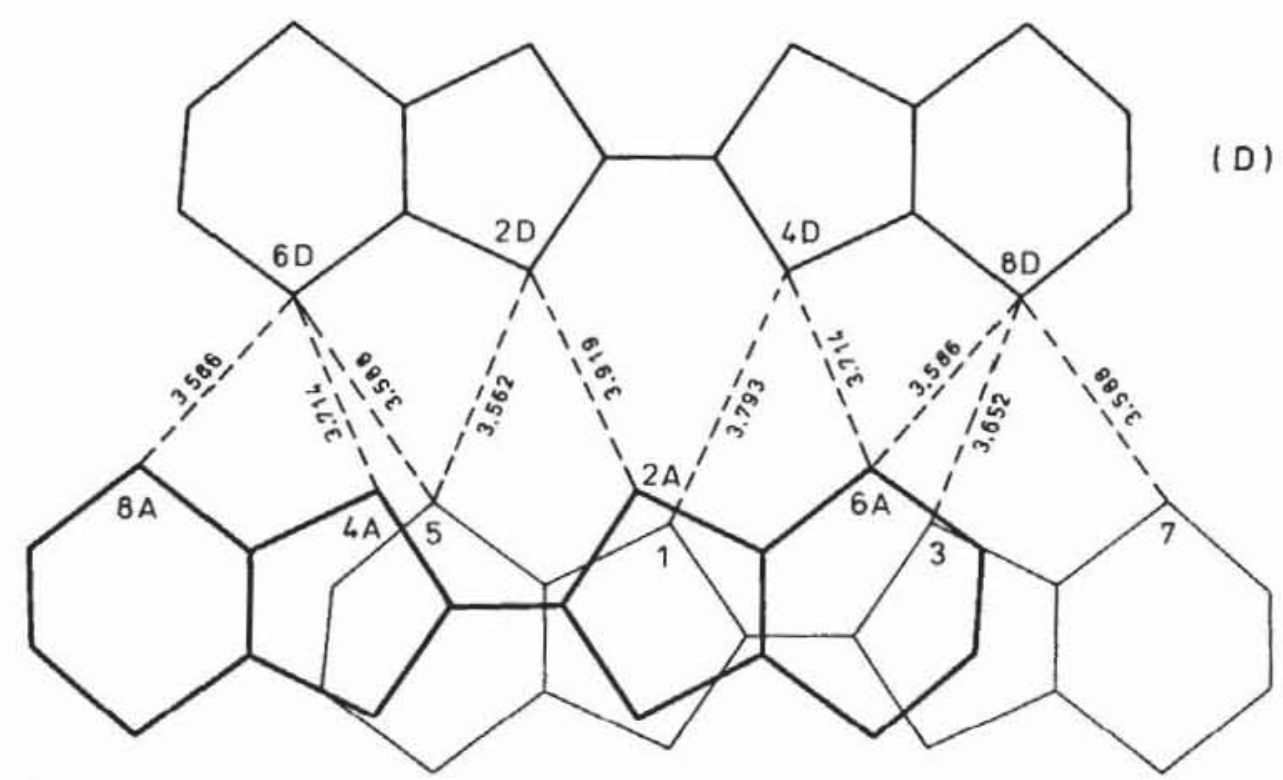

b)

Fig. 2. Comparison of interstack and intrastack relations in the $\mathrm{IBr}_{2}^{-}$(a) and $\mathrm{I}_{2} \mathrm{Br}^{-}$(b) salts. Molecules (0) are plotted from the coordinates in Table II (a) and III (b). Molecules (A) are generated by the symmetry operation $1-x, 2-y, 1-z$, (D) by $1+x, y, z$. Labeled atoms are the corresponding $\mathrm{S}$ atoms. Estimated standard deviations are around $0.005 \AA$ in (a) and $0.003 \AA$ in (b). In the $\mathrm{IBr}_{2}{ }^{-}$salt (a) the shortest intrastack $\mathrm{S} \cdots \mathrm{S}$ contact is between $\mathrm{S}(1)$ and $\mathrm{S}(2 \mathrm{~A}), 3.991 \AA$. All others are larger than $4 \AA$, as in the $\mathrm{I}_{2} \mathrm{Br}^{-}$salt (b). 


\section{a) $\mathrm{I}-\mathrm{I}-\mathrm{Br}^{-}$Salt}

$I-I b r$
$S(1)-C(1)$
$S(2)-C(1)$
$S(3)-C(2)$
$S(4)-C(2)$
$S(5)-C(3)$
$S(6)-C(4)$
$S(7)-C(5)$
$S(8)-C(6)$
$C(1)-C(2)$
$C(5)-C(6)$
$C(9)-C(10)$

$\mathrm{C}(1)-\mathrm{S}(2)-\mathrm{C}(4)$

$C(2)-S(4)-C(6)$

$\mathrm{C}(4)-\mathrm{S}(6)-\mathrm{C}(8)$

$C(6)-S(8)-C(10)$

$\mathrm{S}(1)-\mathrm{C}(1)-\mathrm{C}(2)$

$S(3)-C(2)-S(4)$

$S(4)-C(2)-C(1)$

$\mathrm{S}(1)-\mathrm{C}(3)-\mathrm{C}(4)$

$S(2)-C(4)-S(6)$

$S(6)-C(4)-C(3)$

$\mathrm{S}(3)-\mathrm{C}(5)-\mathrm{C}(6)$

$S(4)-C(6)-S(8)$

$\mathrm{S}(8)-\mathrm{C}(6)-\mathrm{C}(5)$

$S(6)-C(8)-C(7)$

$S(8)-C(10)-C(9)$

b) $\mathrm{Br}-\mathrm{I}-\mathrm{Br}^{-}$Salt

\section{$\mathrm{I}-\mathrm{Br}$}

$S(1)-C(1)$

$S(2)-C(1)$

$S(3)-C(2)$

$S(4)-C(2)$

$S(5)-C(3)$

$S(6)-C(4)$

$S(7)-C(5)$

$\mathrm{S}(8)-\mathrm{C}(6)$

C(1) $-\mathrm{C}(2)$

C(5)-C(6)

$C(9)-C(10)$

$\mathrm{C}(1)-\mathrm{S}(2)-\mathrm{C}(4)$

$C(2)-S(4)-C(6)$

$\mathrm{C}(4)-\mathrm{S}(6)-\mathrm{C}(8)$

$\mathrm{C}(6)-\mathrm{S}(8)-\mathrm{C}(10)$

$S(1)-C(1)-C(2)$

$S(3)-C(2)-S(4)$

$S(4)-C(2)-C(1)$

$S(1)-C(3)-C(4)$

$S(2)-C(4)-S(6)$

$S(6)-C(4)-C(3)$

$S(3)-C(5)-C(6)$

$S(4)-C(6)-S(8)$

$S(8)-C(6)-C(5)$

$S(6)-C(8)-C(7)$

$S(8)-C(10)-C(9)$

$$
\begin{aligned}
& 2.852(1) \\
& 1.742(5) \\
& 1.736(6) \\
& 1.743(6) \\
& 1.732(5) \\
& 1.742(5) \\
& 1.741(6) \\
& 1.748(5) \\
& 1.746(5) \\
& 1.356(7) \\
& 1.344(8) \\
& 1.289(15)
\end{aligned}
$$

95.8(3)

95.2(3)

$103.2(3)$

$101.0(4)$

$122.9(4)$

$115.0(3)$

$122.0(4)$

$117.2(4)$

$115.0(3)$

128.1(4)

$116.8(4)$

$114.4(3)$

128.4(4)

$119.8(5)$

127.1(7)

\subsection{4(1)}

$1.722(12)$

1.743(13)

$1.727(12)$

1.763(12)

$1.747(11)$

$1.744(12)$

$1.756(11)$

$1.759(12)$

$1.352(15)$

1.332(17)

$1.389(24)$

95.0(6)

94.4(5)

$103.0(7)$

101.3(7)

$122.9(10)$

114.7(6)

$121.6(9)$

$117.8(8)$

114.7(7)

128.7(9)

$117.5(8)$

$113.5(7)$

129.3(8)

121.3(12)

$117.6(12)$
$1.747(5)$

$1.742(5)$

$1.750(5)$

$1.744(5)$

$1.760(7)$

$1.770(7)$

$1.766(10)$

$1.753(11)$

$1.342(8)$

1.439(9)

$\mathrm{C}(1)-\mathrm{S}(1)-\mathrm{C}(3) \quad 95.3(3)$

$\mathrm{C}(2)-\mathrm{S}(3)-\mathrm{C}(5) \quad 95.0(2)$

$\mathrm{C}(3)-\mathrm{S}(5)-\mathrm{C}(7) \quad 100.4(3)$

$\mathrm{C}(5)-\mathrm{S}(7)-\mathrm{C}(9) \quad 100.6(4)$

$S(1)-C(1)-S(2) \quad 114.7(3)$

$\mathrm{S}(2)-\mathrm{C}(1)-\mathrm{C}(2) \quad 122.3(4)$

$\mathrm{S}(3)-\mathrm{C}(2)-\mathrm{C}(1) \quad 123.0(4)$

$S(1)-C(3)-S(5) \quad 114.6(3)$

$\mathrm{S}(5)-\mathrm{C}(3)-\mathrm{C}(4) \quad 128.2(4)$

$S(2)-C(4)-C(3) \quad 116.9(4)$

$S(3)-C(5)-S(7) \quad 114.5(3)$

$S(7)-C(5)-C(6) \quad 128.7(4)$

$\mathrm{S}(4)-\mathrm{C}(6)-\mathrm{C}(5) \quad 117.2(4)$

$S(5)-C(7)-C(8) \quad 119.0(4)$

$S(7)-C(9)-C(10) \quad 126.4(7)$

$\begin{array}{ll}S(1)-C(3) & 1.733(11) \\ S(2)-C(4) & 1.753(11) \\ S(3)-C(5) & 1.744(11) \\ S(4)-C(6) & 1.751(11) \\ S(5)-C(7) & 1.805(16) \\ S(6)-C(8) & 1.772(16) \\ S(7)-C(9) & 1.856(19) \\ S(8)-C(10) & 1.789(18) \\ C(3)-C(4) & 1.334(17) \\ C(7)-C(8) & 1.381(21)\end{array}$

$\mathrm{C}(1)-\mathrm{S}(1)-\mathrm{C}(3) \quad 95.6(6)$

$\mathrm{C}(2)-\mathrm{S}(3)-\mathrm{C}(5) \quad 95.3(6)$

$\mathrm{C}(3)-\mathrm{S}(5)-\mathrm{C}(7) \quad 100.6(6)$

$\mathrm{C}(5)-\mathrm{S}(7)-\mathrm{C}(9) \quad 100.4(7)$

$\mathrm{S}(1)-\mathrm{C}(1)-\mathrm{S}(2) \quad 115.1(6)$

$\mathrm{S}(2)-\mathrm{C}(1)-\mathrm{C}(2) \quad 122.0(9)$

$\mathrm{S}(3)-\mathrm{C}(2)-\mathrm{C}(1) \quad 123.6(9)$

$\mathrm{S}(1)-\mathrm{C}(3)-\mathrm{S}(5) \quad 115.0(7)$

$\mathrm{S}(5)-\mathrm{C}(3)-\mathrm{C}(4) \quad 127.3(9)$

$\mathrm{S}(2)-\mathrm{C}(4)-\mathrm{C}(3) \quad 116.5(9)$

$S(3)-C(5)-S(7) \quad 114.4(7)$

$\mathrm{S}(7)-\mathrm{C}(5)-\mathrm{C}(6) \quad 128.1(8)$

$\mathrm{S}(4)-\mathrm{C}(6)-\mathrm{C}(5) \quad 117.2(8)$

$\mathrm{S}(5)-\mathrm{C}(7)-\mathrm{C}(8) \quad 118.6(10)$

$S(7)-C(9)-C(10) \quad 117.6(11)$
Table IV. Bond distances $(\AA)$ and angles $\left({ }^{\circ}\right)$. 
and angles in the BEDT-TTF cations are given in Table IV, Fig. 1 shows the numbering scheme. The anions are linear by symmetry. There are stacks of the cations, where the molecules along a stack are related by inversion centers. Two different modes of overlap along a stack are possible, and these are actually observed (Figs 2 and 3 ). The more important
S $\cdots$ S contacts occur between adjacent stacks than within a stack, giving the compounds a pronounced two-dimensional character. The pertinent interstack S...S distances are shown in Figs 2 and 3. An impression of the interstack relations is given in Fig. 4. The cation sheets are separated by layers of anions, Fig. 5.
(B)

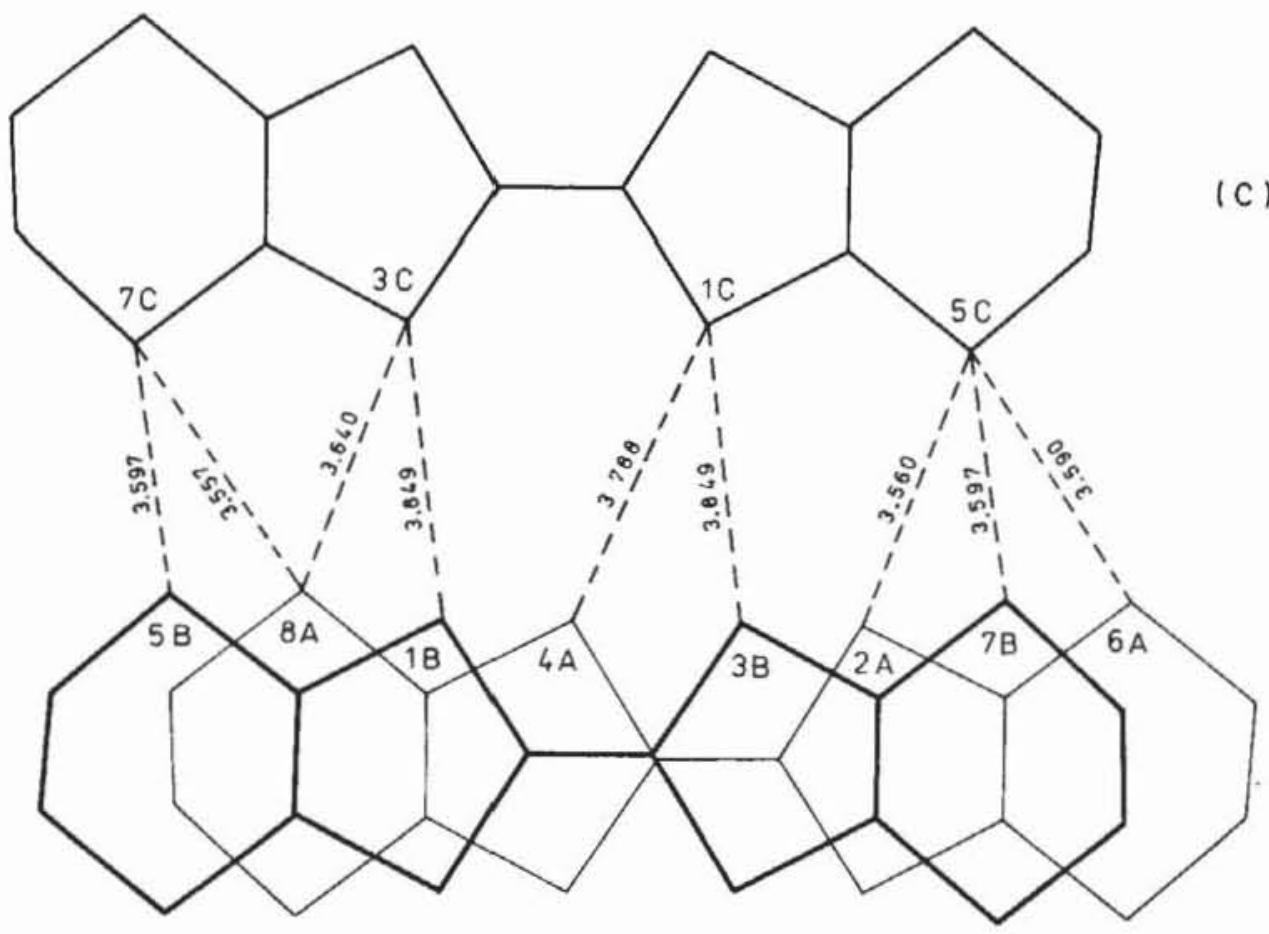

b)

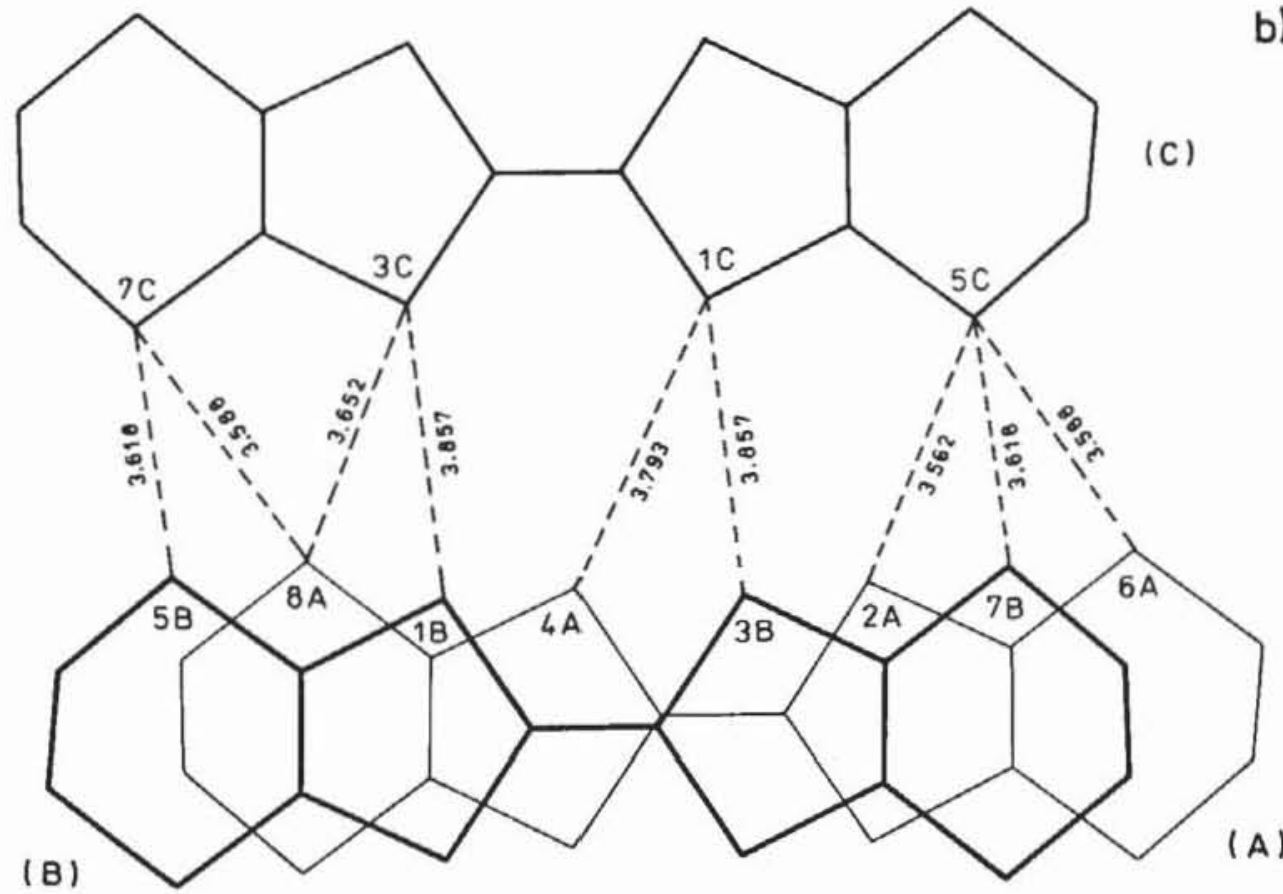

a)
Fig. 3. Analogous to Fig. 2. (B) is generated by the operation $1+x, 1+y, z,(\mathrm{C})$ by $2-x, 2-y$, $1-z$. In the $\mathrm{IBr}_{2}^{-}$salt (a) shortest intrastack S...S contacts are: $\mathrm{S}(2 \mathrm{~A})-\mathrm{S}(3 \mathrm{~B}) 3.73$, $S(4 A)-S(1 B) 3.781$, $\mathrm{S}(4 \mathrm{~A})-\mathrm{S}(3 \mathrm{~B}) 3.786 \AA$. Corresponding values for the $\mathrm{I}_{2} \mathrm{Br}^{-}$ salt (b) are $3.763,3.792$, and $3.765 \AA$, respectively. 
(D)

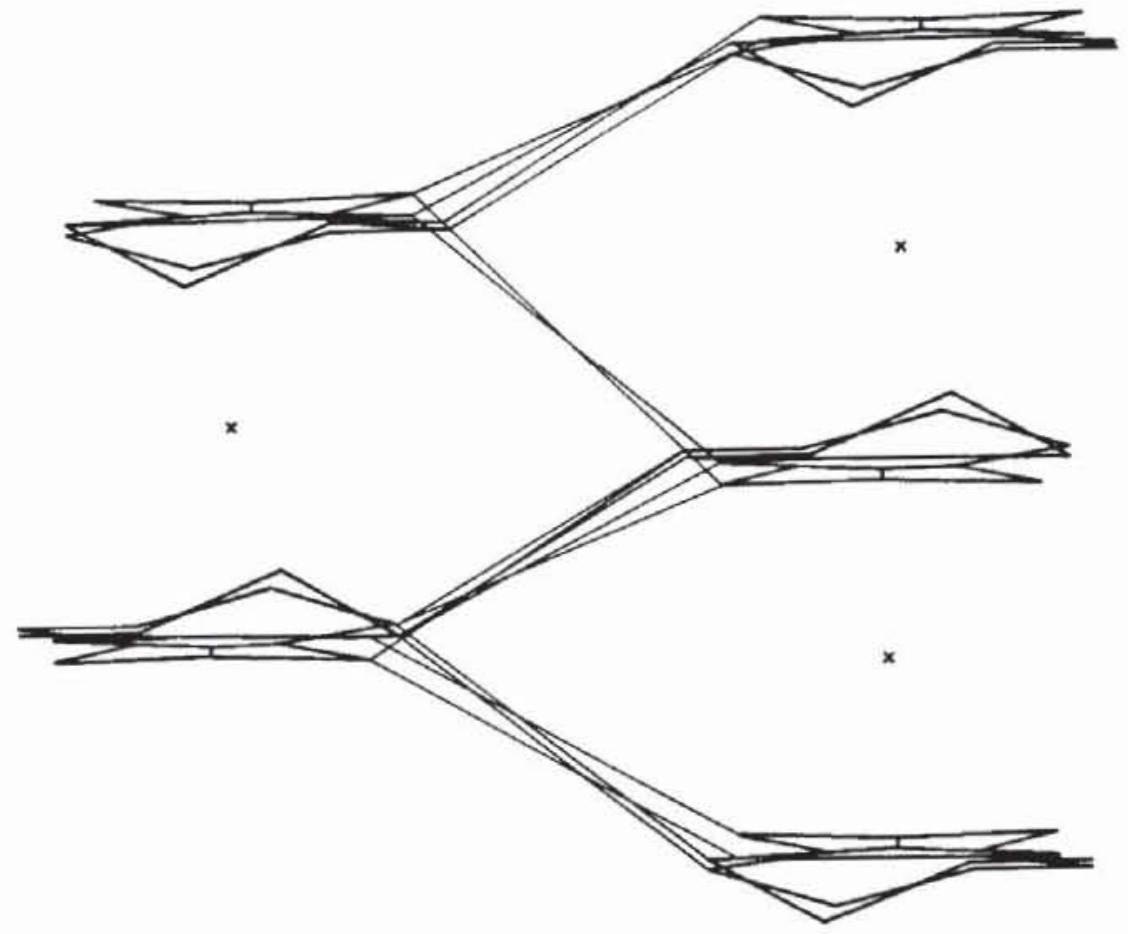

(A)

Fig. 4. Section of the cation sheet seen along the long axis of the cations. Interstack S $\cdots S$ contacts $<4 \AA$ are indicated. The crosses stand for crystallographic inversion centers.

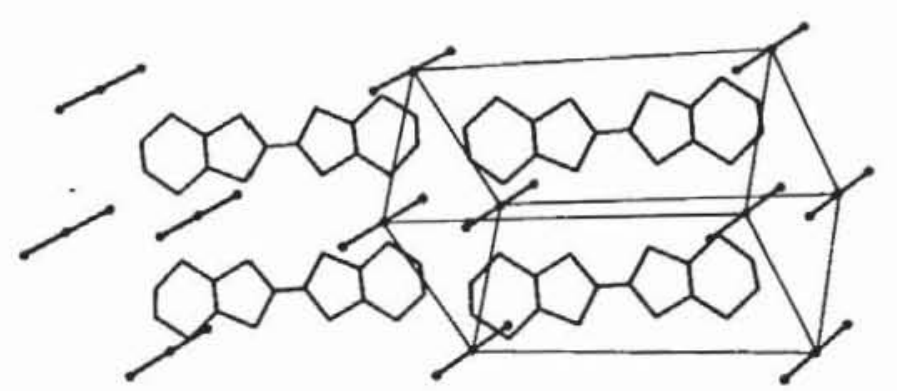

Fig. 5. Projection of the structure perpendicularly to the plane through the BEDT-TTF $S$ atoms.

These results differ in some details from those published for the $\mathrm{IBr}_{2}{ }^{-}$salt [15]: We find a somewhat larger unit cell of $\mathrm{V}=834.7 \AA^{3}$, as compared with $\mathrm{V}=828.7 \AA^{3}$. This is reflected in the $\mathrm{I}-\mathrm{Br}$ distance, 2.764(1) $\AA$, slightly larger than the reported 2.702(1) $\AA$. The interstack S $\cdots$. S contacts seem to be less influenced: the shortest value, 3.557(5) $\AA$, compares well with the shortest distance in [15], 3.559 (2) $\AA$. As to be expected, the salt with the disordered $(\mathrm{I}-\mathrm{I}-\mathrm{Br})^{-}$anion has a larger unit cell, $\mathrm{V}=$ $846.5 \AA^{3}$. The mean bond distance within the anion is 2.852 (1) $\AA$, closer to the value in the $\mathrm{I}_{3}{ }^{-}$salts, 2.912(1) $\AA$ [15], than to $\mathrm{IBr}_{2}{ }^{-}$.

The influence of the increased anion volume on the intermolecular $\mathrm{S} \cdots \mathrm{S}$ contacts is not clear-cut, however (Figs 2 and 3). Even though most of the $\mathrm{S} \cdots \mathrm{S}$ contacts are shorter in the $\mathrm{IBr}_{2}{ }^{-}$than in the $\mathrm{I}_{2} \mathrm{Br}^{-}$salt, some are actually larger. Extreme examples are: $\mathrm{S}(8 \mathrm{~A}) \cdots \mathrm{S}(7 \mathrm{C}), 3.557(5) \AA$ for $\mathrm{IBr}_{2}{ }^{-}$and $3.588(3) \AA$ for $\mathrm{I}_{2} \mathrm{Br}$, and $\mathrm{S}(4 \mathrm{~S}) \cdots \mathrm{S}(6), 3.734(5) \AA$ for $\mathrm{IBr}_{2}^{-}$and 3.714(3) $\AA$ for $\mathrm{I}_{2} \mathrm{Br}^{-}$. Hence the change of the anion volume does not affect all $\mathrm{S} \cdots \mathrm{S}$ contacts equally. The different anion shapes lead to slight variations in the cation arrangement, with different consequences for $\mathrm{S} \cdots \mathrm{S}$ contacts.

Besides the $\mathrm{I}_{2} \mathrm{Br}^{-}$-phase described here we have also found a crystal with a modulation of this structure: Rows of superstructure reflections are visible on a rotation photograph around the $c$-axis, but not on photographs with rotation around $a$ or $b$. The period of the modulation along the $c$-axis is most likely incommensurate with $c$ and amounts to about $4.5 c-4.7 c$. More precise structural information could not be obtained.

\section{Physical investigations}

Thermopower measurements of crystals of $\beta$-(BEDT-TTF $)_{2} \mathrm{IIBr}$ and $\beta$-(BEDT-TTF $)_{2} \mathrm{BrIBr}$ show an analogous temperature dependence to that already observed for $\beta$-(BEDT-TTF $)_{2} I_{3}$ crystals [16]. The ESR line width at room temperature lies be- 
tween 20-25 Gauß for all $\beta$-phases and can be used to discriminate between crystals of $\alpha$ - and $\beta$-phases (line width of the $\alpha$-phase $70-110 \mathrm{Gau} \beta$ ). These ESR measurements show a temperature independent susceptibility between 300 and $4.2 \mathrm{~K}$ [17].

Due to the small size $(0.3 \times 0.2 \times 0.2 \mathrm{~mm})$ of the crystals of $\beta$-(BEDT-TTF $)_{2} \mathrm{IIBr}$ and of $\beta$-(BEDT-TTF $)_{2} \mathrm{BrIBr}$ it was not possible to carry out dc conductivity measurements. Nevertheless investigations of the ac susceptibility down to $1.3 \mathrm{~K}$ did not show any evidence of an onset of diamagnetic shielding currents. This result was confirmed even down to $0.1 \mathrm{~K}$ by C. P. Heidmann and K. Andres [18], indicating that none of the investigated samples of $\beta$-(BEDT-TTF)IIBr and $\beta$-(BEDT-TTF) $\mathrm{BrIBr}$ became superconducting, in contrast to samples of $\beta$-(BEDT-TTF $)_{2} \mathrm{I}_{3}$ (3) and crystals of $\beta$-(BEDT-TTF $)_{2} \mathrm{BrIBr}$ investigated by Williams et al. [15] and Murota et al. [19] which became superconducting at around $2.5 \mathrm{~K}$. At this moment it is not clear to us whether these different results are due to the small differences in the structure of our crystals, compared with those reported by Williams et al. [4].

\section{Conclusion}

As pointed out earlier [20] electrocrystallization of BEDT-TTF in the presence of trihalide ions poses a special problem: In contrast to the use of counterions $\mathrm{ClO}_{4}^{-}, \mathrm{ReO}_{4}^{-}, \mathrm{AsF}_{6}{ }^{-}$e.g. anodic oxidation of the anions and the reactivity of the oxidation products has to be taken into account. This synthetic complication might explain some discrepancies reported for the structure and physical properties of some of these materials: We found an additional modulated phase of $\beta$-(BEDT-TTF $)_{2} \mathrm{I}_{2} \mathrm{Br}$ besides the known "regular" phase.

This work has been supported by Stiftung Volkswagenwerk, Hannover, and by Fonds der Chemischen Industrie, Frankfurt. We would like to thank K. Andres and C. P. Heidmann, Walther-MeissnerInstitut für Tieftemperaturforschung, Garching, for the ac susceptibility measurements down to $0.1 \mathrm{~K}$.
[1] E. B. Yagubskii, I. F. Shchegolev, V. N. Laukhin, P. S. Kononovich, A. K. Kartsovnik, A. V. Zvarykina, and L. I. Buravov, Zh. Ehsp. Teor. Fiz. Pis'ma Red. 39, 12 (1984).

[2] J. M. Williams, T. M. Emge, H. H. Wang, M. A. Beno, P. T. Copps, L. N. Hall, K. D. Carlson, and G. W. Crabtree, Inorg. Chem. 23, 2558 (1984).

[3] a) H. Schwenk, F. Gross, C. P. Heidmann, K. Andres, D. Schweitzer, and H. J. Keller, Proceedings of the Intern. Conf. on the Physics and Chemistry of Low-Dimensional Synthetic Metals, Abano Terme 1984, Mol. Cryst. Liq. Cryst. 119, 329 (1985);

b) H. Schwenk, C. P. Heidmann, F. Gross, E. Hess, K. Andres, D. Schweitzer, and H. J. Keller, Phys. Rev. B 31, 3138 (1985).

[4] T. J. Emge, H. H. Wang, M. A. Beno, P. C. W. Leung, M. A. Firestone, H. C. Jenkins, J. D. Cook, K. D. Carlson, J. M. Williams, E. L. Venturini, L. J. Azevedo, and J. E. Schörber, Inorg. Chem. 24, 1736 (1985).

[5] M. Tokumoto, K. Murata, H. Anzai, H. Bando, G. Saito, and T. Ishiguro, Synmetalls III, Los Alamos 1985.

[6] M. Hiller, Dissertation, University of Heidelberg 1985.

[7] a) K. Hartke, Th. Kissel, I. Quante, and R. Matusch, Chem. Ber. 113, 1898 (1980);

b) M. Mizuno, A. Garito, and M. Cava, J. Chem. Soc. Chem. Commun. 1978, 18.

[8] R. E. Buckles and J. P. Yuk, J. Am. Chem. Soc. 75, 5048 (1953).

[9] F. Ephraim, Chem. Ber. 50, 1069 (1917).

[10] H. J. Keller, D. Nöthe, H. Pritzkow, D. Wehe, M. Werner, P. Koch, and D. Schweitzer, Mol. Cryst. Liq. Cryst. 62, 181 (1980).
[11] K. Bender, I. Hennig, D. Schweitzer, K. Dietz, H. Endres, and H. J. Keller, Mol. Cryst. Liq. Cryst. 108, 359 (1984).

[12] T. Mori, A. Kobayashi, Y. Sasaki, H. Kobayashi, G. Saito, and H. Inokuchi, Chem. Lett. 1984, 957.

[13] G. M. Sheldrick, SHELXTL. An integrated System for solving, refining, and displaying crystal structures from diffraction data. Univ. Göttingen, FRG 1983.

[14] International Tables for X-ray Crystallography. Vol. IV. Kynoch Press, Birmingham 1974.

[15] J. M. Williams, H. H. Wang, M. A. Beno, T. J. Emge, L. M. Sowa, P. T. Copps, F. Behroozi, L. N. Hall, K. D. Carlson, and G. W. Crabtree, Inorg. Chem. 23, 3839 (1984).

[16] I. Hennig, K. Bcnder, D. Schweitzer, K. Dietz, H. Endres, H. J. Keller, A. Gleitz, and H. W. Helberg, Proceedings of the International Conference on the Physics and Chemistry of Low-Dimensional Synthetic Metals, Abano Terme 1984, Mol. Cryst. Liq. Cryst. 119, 337 (1985).

[17] P. Bele, H. Brunner, D. Schweitzer, and H. J. Keller, to be published.

[18] C. P. Heidmann and K. Andres, Walther-MeissnerInstitut für Tieftemperaturforschung, Garching, BRD, private communication.

[19] K. Murata, M. Tokumoto, H. Bando, H. Tanino, H. Anzai, N. Kinoshita, K. Kajimura, G. Saito, and T. Ishiguro, Proc. Int. Conf. on Materials and Mechanisms of Superconductivity, Ames Iowa 1985, to be published in Physica B+C.

[20] H. J. Keller, Synmetalls III, Los Alamos 1985. 